\title{
Délos : étude de matériel - 2017
}

\section{Pavlos Karvonis et Vyron Antoniadis}

\section{OpenEdition \\ Journals}

Édition électronique

URL : http://journals.openedition.org/baefe/1922

DOI : $10.4000 /$ baefe. 1922

ISSN : 2732-687X

Éditeur

ResEFE

\section{Référence électronique}

Pavlos Karvonis, Vyron Antoniadis, « Délos : étude de matériel - 2017 » [notice archéologique], Bulletin archéologique des Écoles françaises à l'étranger [En ligne], Grèce, mis en ligne le 23 décembre 2020, consulté le 22 mars 2021. URL : http://journals.openedition.org/baefe/1922 ; DOI : https://doi.org/ $10.4000 /$ baefe. 1922

Ce document a été généré automatiquement le 22 mars 2021.

\section{cc)}

Le Bulletin archéologique des Écoles françaises à l'étranger est mise à disposition selon les termes de la Licence Creative Commons Attribution - Pas d'Utilisation Commerciale - Pas de Modification 4.0 International. 


\title{
Délos : étude de matériel - 2017
}

\author{
Pavlos Karvonis et Vyron Antoniadis
}

\section{NOTE DE L'AUTEUR}

Autorité nationale présente : Éphorie des Cyclades

Établissements porteurs de l'opération : EFA

\section{Données scientifiques produites :}

Délos par l'EFA

Web SIG de Délos

1 Du 20 août 2017 au $1^{\text {er }}$ septembre 2017, Vyron Antoniadis (archéologue) a étudié le matériel provenant du nettoyage, qu'il avait effectué en 2015 dans le Magasin des colonnes. Le matériel comportait de la céramique, surtout des fragments d'amphores, des clous, deux tuiles et un fragment de mosaïque. Pendant cette première campagne, la céramique a été nettoyée, dessinée et photographiée. Vingt dessins de vases ont été réalisés. Des tessons appartenant probablement à cinq amphores différentes ont été identifiés (fig. 1-2, 4). Aucune n'est entièrement conservée, mais il semble qu'il s'agissait d'amphores de transport, de grande taille. Ces amphores sont différentes entre elles du point de vue typologique, mais elles appartiennent toutes à des types bien connus à Délos. 
Fig. 1. Dessin d'amphore.

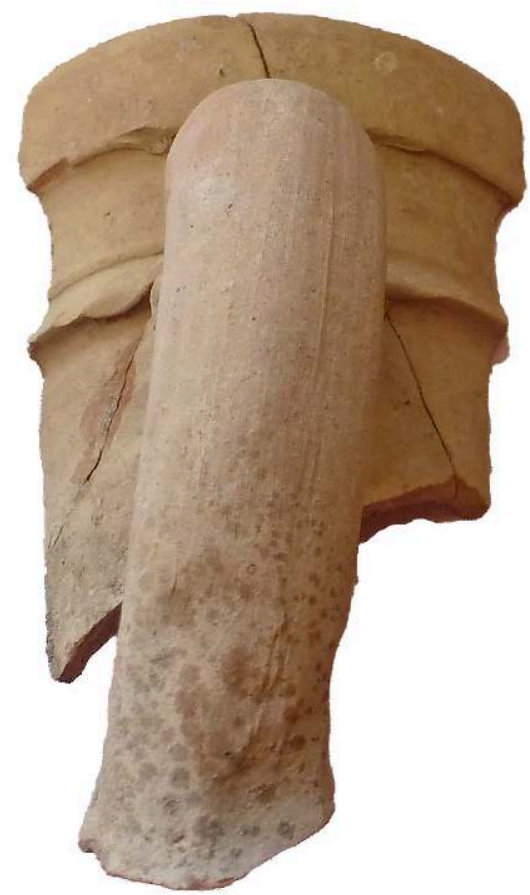

EFA.

Fig. 2. Anses et lèvres de différents types d'amphores.
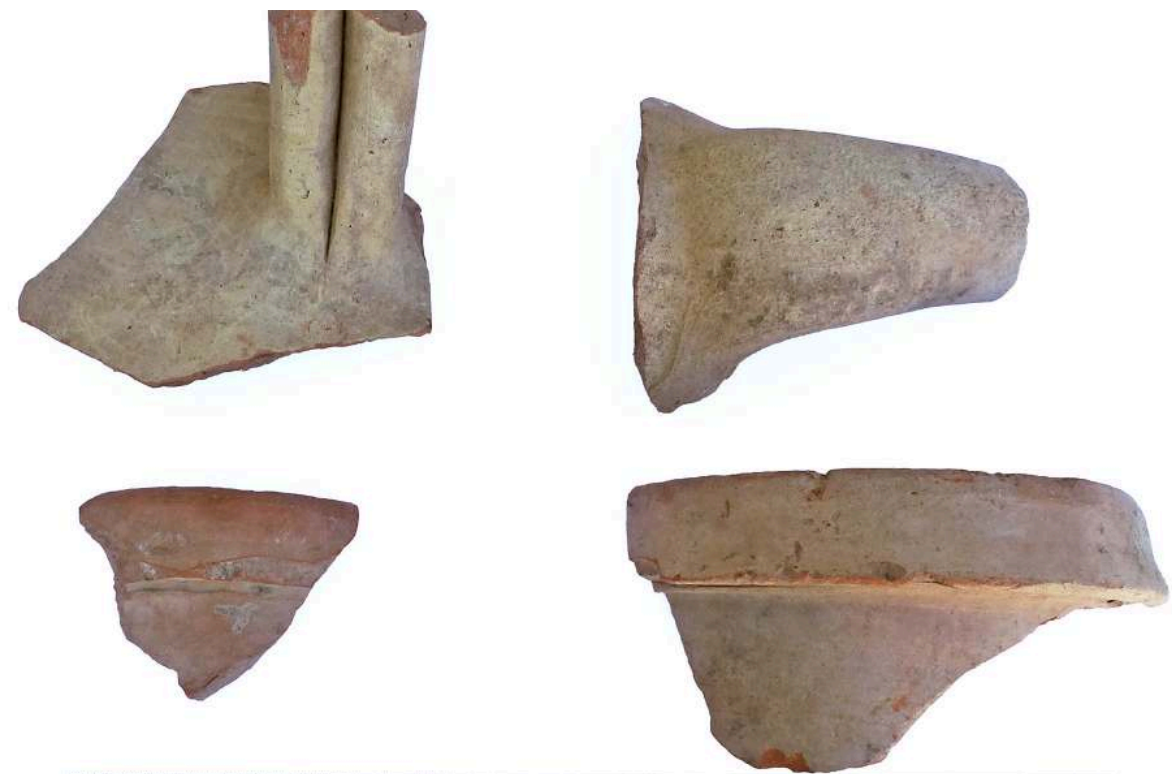
.... EFA. 
2 La céramique fine (fig. 3-4) comprenait des plats, dont certains étaient à vernis noir, des coupes, des tessons de vases à relief, des bases de vases ouverts et le col d'un unguentarium. La céramique date de la fin du II $^{\mathrm{e}}$ et du début du $\mathrm{I}^{\mathrm{er}}$ siècle av. J.-C.

Fig. 3. Anse d'amphore et tessons de petits vases.

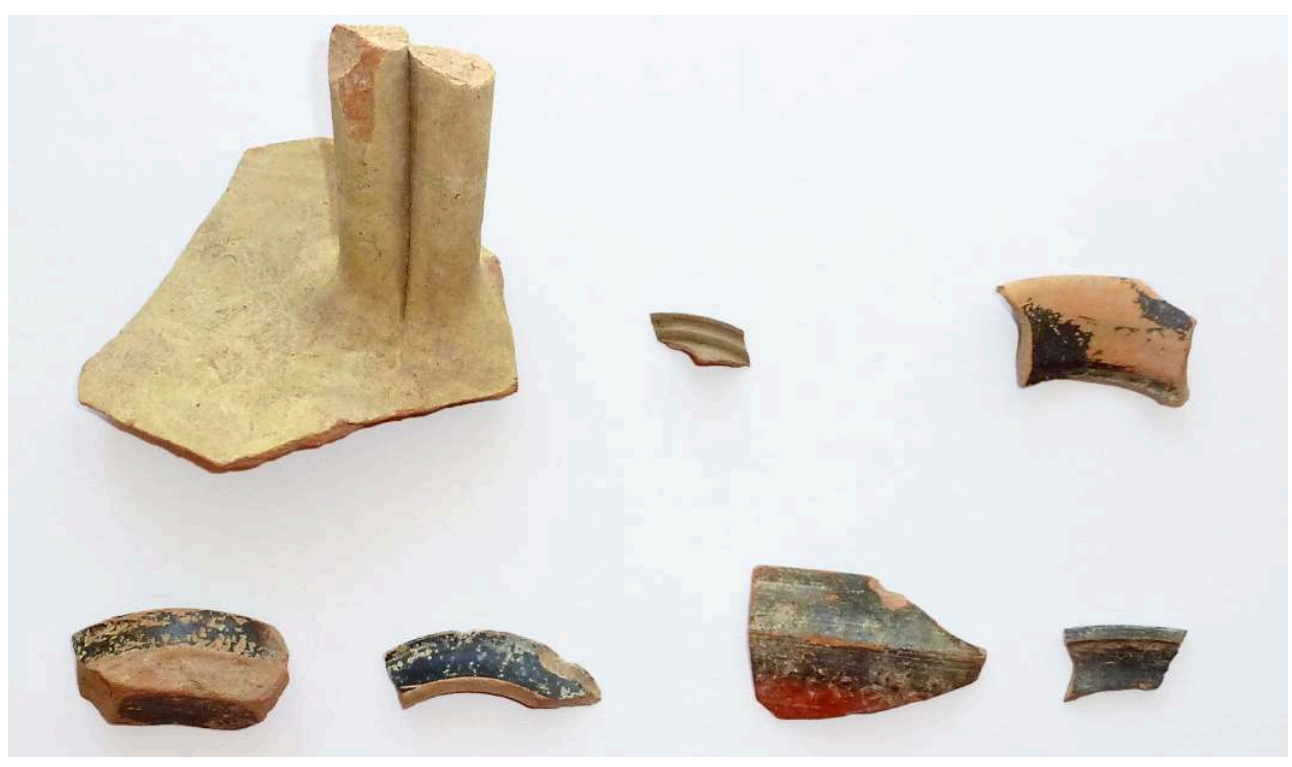

EFA.

Fig. 4. Tessons de petits vases.

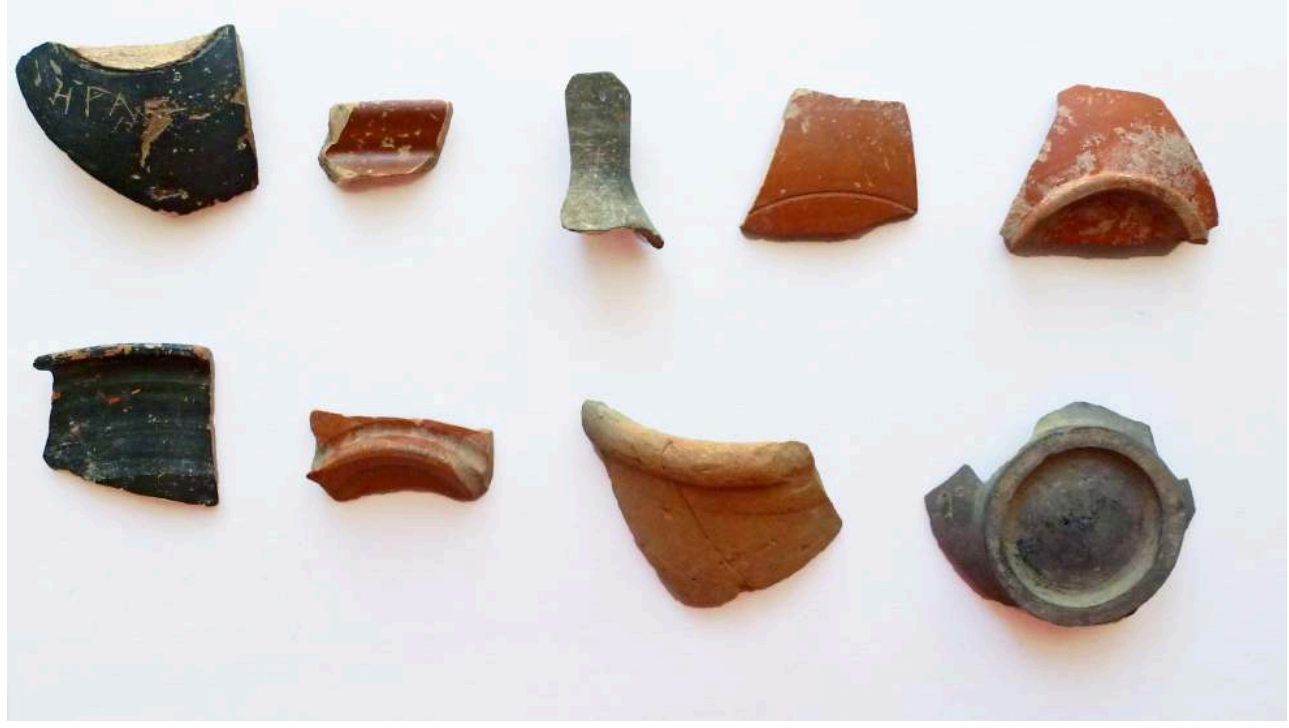

EFA.

3 Le fragment de la base d'un petit vase à vernis noir porte un graffito (fig. 5). Il s'agit du nom masculin HPA $\Sigma$, qui se rencontre deux fois dans la prosopographie délienne. Une fois à la fin du second (ID 2631, 1.21) et une deuxième fois à la fin du premier siècle av. J.-C (ID 2255, 1. 4). 
Fig. 5. Tesson inscrit.
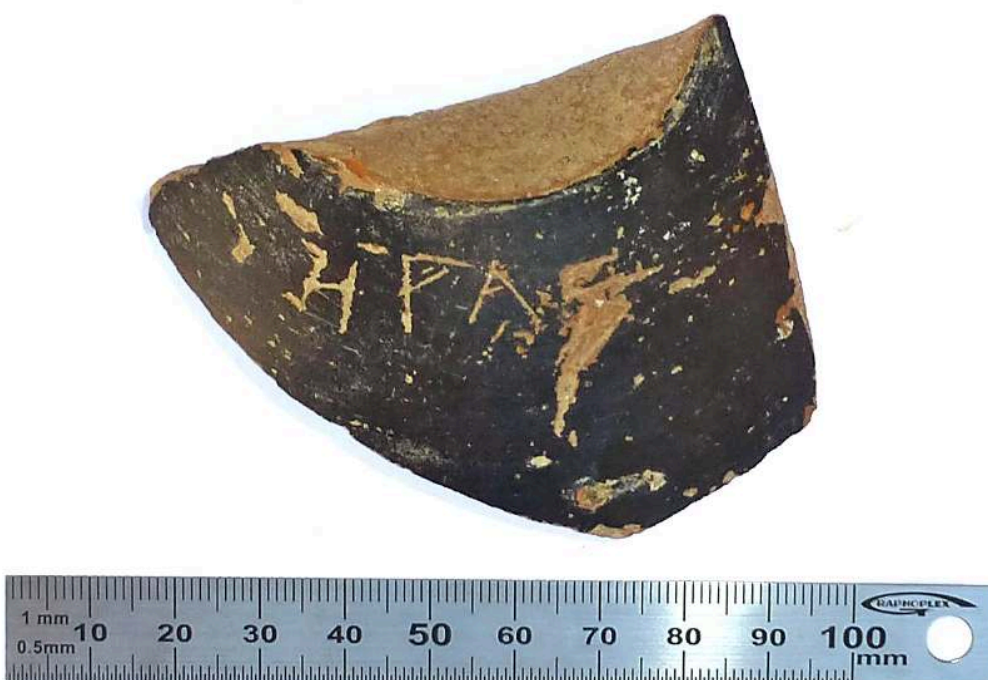

EFA.

4 Dix clous en fer ont été retrouvé, dont un, long de $11 \mathrm{~cm}$, est conservé en entier (fig. 6). Ils appartenaient à une porte.

Fig. 6. Clous.
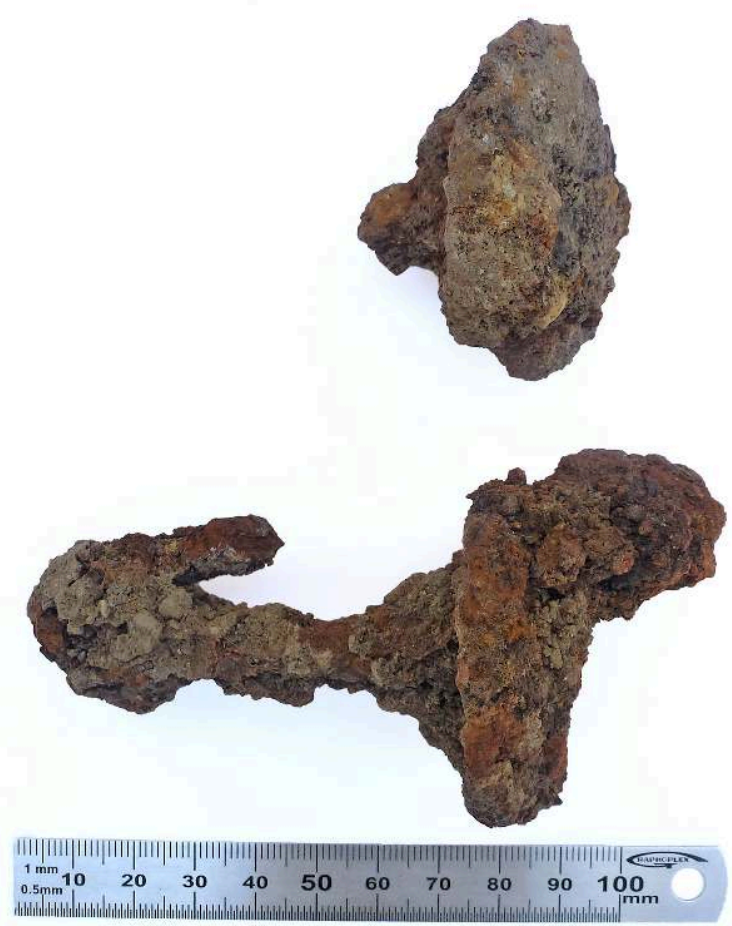

EFA.

5 Le fragment de mosaïque provenait peut-être de l'étage ou du toit de l'édifice. 
INDEX

Thèmes : EFA

sujets https://ark.frantiq.fr/ark:/26678/pcrtEznNgQ3h63, https://ark.frantiq.fr/ark:/26678/ pcrtVFfTq3JlGu, https://ark.frantiq.fr/ark:/26678/pcrtMbtcPfoUvx

lieux https://ark.frantiq.fr/ark:/26678/pcrtXvsaqTQa4J

chronologie https://ark.frantiq.fr/ark:/26678/pcrtNzYn31IIAZ

Année de l'opération : 2017

\section{AUTEURS}

\section{PAVLOS KARVONIS}

Académie des sciences d'Athènes

\section{VYRON ANTONIADIS}

National Hellenic Research Foundation 